\title{
EFEKTIVITAS METODE IMLA' TERHADAP PENINGKATAN KEMAMPUAN SISWA DALAM MENULIS BAHASA ARAB
}

\author{
Imam Asrofi \\ Program Studi Pendidikan bahasa Arab, Universitas Islam Nusantara, Bandung \\ Asyrofy79@gmail.com \\ Abdul Halim \\ Program Studi Pendidikan bahasa Arab, Universitas Islam Nusantara, Bandung \\ abdulhalimuninus@gmail.com
}

Diterima tanggal 29-11-2021

Publish tanggal 16-12-2021

\begin{abstract}
Facts on the ground, there are still many students who find it difficult to write in Arabic according to the rules of writing style caused by differences in intellectual abilities, physical abilities, family backgrounds, habits and learning approaches that are sometimes very striking between one student and another student. Therefore, learning techniques are needed that can improve students' ability to write Arabic. IMLA is a learning technique to justify as well as improve writing that needs improvement. The purpose of this study is based on the aim of obtaining empirical data regarding the effectiveness of the application of the IMLA method in writing Arabic for class XI students of senior High School Cililin, Sumur Bandung, West Bandung. This research is an experimental research type. The population in this study was class XI senior High School Cililin, Sumur Bandung, West Bandung, amounting to 37 students. The research data was obtained by presenting a dictation skill test IMLA and proved by the results of the $t$-test. From the results of data analysis, it can be obtained $t$-count (10.87) $>t$ table (1.687) with a significant level of 5\%. West in writing Arabic.
\end{abstract}

Keywords: Language, Writing Ability, IMLA Method

\begin{abstract}
Abstrak
Melihat fakta dilapangan, masih banyak para pelajar yang kesulitan untuk menulis dalam bahasa Arab sesuai dengan aturan-aturan gaya penulisan yang disebabkan oleh perbedaan kemampuan intelektual, kemampuan fisik, latar belakang keluarga, kebiasaan dan pendekatan belajar yang terkadang sangat mencolok antara satu siswa dengan siswa yang lainnya. Oleh sebab itu, dibutuhkan teknik pembelajaran yang mampu meningkatkan kemampuan siswa dalam menulis bahasa Arab. Imla' merupakan suatu teknik pembelajaran untuk membenarkan sekaligus memperbaiki tulisan yang membutuhkan perbaikanTujuan dalam penelitian ini didasarkan pada tujuan untuk mendapatkan data-data secara empiris mengenai keefektifan penerapan metode imla dalam menulis bahasa Arab siswa kelas XI MA Sumur Bandung Cililin Kabupaten Bandung Barat. Penelitian ini merupakan jenis penelitian eksperimental. Populasi dalam penelitian ini adalah siswa kelas XI MA Sumur Bandung Cililin Kabupaten Bandung Barat yang berjumlah 37 siswa. Data penelitian ini diperoleh dengan cara menyajikan tes keterampilan dikte (imla'), dan dibuktikan dengan hasil uji-t. Dari hasil analisis data dapat diperoleh t-hitung $(10,87)>t$-tabel $(1,687)$ dengan taraf signifikan $\alpha$ 5\%. Hasil penelitian ini membuktikan bahwa metode imla' efektif dalam meningkatkan kemampuan siswa kelas XI MA Sumur Bandung Cililin Kabupaten Bandung Barat dalam menulis bahasa Arab.
\end{abstract}

Kata Kunci: Bahasa, Kemampuan Menulis, Metode Imla' 


\section{Pendahuluan}

Bahasa Arab adalah fondasi utama yang menyangga kehidupan dan eksistensi kita. ia termasuk jalan terbaik untuk mengenali identitas dan kepribadian bangsa. Sejak zaman dahulu, bahasa Arab merekam suara dan pemikiran kita. Ia merupakan habitat pikiran diman kita hidup didalamnya. Ia merupakan arena pertemuan yang menyambungkan masa lalu, masa kini, dan masa depan.

Bahasa Arab merupakan fondasi terkuat diantara fondasi-fondasi yang menyangga bangunan-bangunan identitas kita. Kita sendiri harus bangga dengan bahasa Arab. Disisi lain, kita juga harus mencintai, merawat dan menjaganya secara konsisten dengan cara-cara yang semestinya. Salah satu caranya dengan menjaga bahasa Arab dari kekeliruan dalam menuturkan dan menuliskannya. Serta menjaganya dari kontaminasi dan redukasi bahasa asing. Kita tidak boleh memandang bahasa Arab hanya sebagai sekumpulan suara pelafalan, ucapan, dan susunan kalimat. Kita harus memperlakukannya sebagai sesuatu yang hidup seperti diri kita.

Menurut Nashir Abdullah Al-Ghali (1991: 51) dalam bukunya "Ususu I'dadi AlKutub At-Ta'limiyah Lighairi An-Nathiqina bi Al-Arabiyah" menjalaskan bahwa yang dimaksud dengan ketrampilan (kemahiran) adalah kecepatan, kedetilan dan kebagusan seseorang dalam melakukan suatu pekerjaan. Jika ada seseorang memiliki kecepatan, kedetilan dan kebagusan dalam berbicara dengan lafal yang fasih, susunan kalimat yang bagus, memperhatikan setiap titik dan koma, mengungkapkannya dengan suara yang pas dan sebagainya, maka pada saat itu kita katakan bahwa dia mahir dalam berbicara. Dengan demikian yang dimaksud dengan kemahiran atau ketrampilan berbahasa adalah kecepatan, kedetilan dan kebagusan seseorang dalam berbahasa.

Keterampilan berbahasa Arab meliputi maharah al-istima', maharah al-kalam, maharah al-qiro'ah dan maharah al-kitabah (Thu'aimah, 2008). Dalam meningkatkan keterampilan sebagaimana diungkapkan oleh Mosleh seorang guru harus terampil dalam memilih metode dan strategi yang sesuai dengan masing-masing keterampilan yang hendak dicapai (Mosleh, 2016), hal itu tidak terlepas dari apa yang diungkapkan oleh Utsamanah bahwa empat keterampilan tersebut tidak mungkin dapat dicapai oleh peserta didik secara sekaligus ('Utsaminah, 2011).

Keterampilan menulis bahasa Arab merupakan keterampilan yang dianggap sulit dalam pembelajaran bahasa Arab. Terkadang santri mudah untuk berbicara akan tetapi sulit untuk menulis. Kesulitan menulis bahasa Arab mulai dari anak kecil hingga dari anak dewasa. Bahkan anak dewasa kesulitan dalam menulis bahasa Arab, karena kurangnya membiasakan menulis bahasa Arab sehari-hari. Dan guru Bahasa Arab juga kurang kreatif dalam penggunaan media pembelajaran. Keterampilan kitabah pada dasarnya mempelajari seperti dasarnya tarakib (kaidah-kaidah Bahasa Arab) seperti jumlah ismiyah, jumlah fi'liyah dan imla'. Karena pondasi belajar maharah kitabah santri bisa mengetahui dan dapat membedakan jumlah ismiyah, jumlah fi'liya dan imla' Yang mana pelajaran dasar kitabah tersebut harus dikokohkan agar santri bisa mempratekkan kitabah. Pembelajaran kitabah salah satunya adalah imla. Pembelajaran 
Imla' merupakan pembelajaran mengenal hamzah. Mulai dari hamzah qotho' dan washol, itu semua awal dari pembelajaran maharah kitabah.

Imla'adalah salah satu materi keahlian khusus yang diberikan untuk membekali para mahasiswa atau peserta didik agar mereka mampu untuk menulis arab dengan baik dan benar. Qowa'idul Imla' dipaparkan terpisah yaitu setelah pemaparan materi khat'araby, tujuannya adalah agar tidak hanya mampu menulis bagus namun juga benar.

\section{Metode Penelitian}

metode yang digunakan dalam penelitian ini adalah metode eksperimental. Penelitian Eksperimen menurut Sukardi (Grasandi, 2010) adalah metode sistematis guna membangun hubungan yang mengandung fenomena sebab akibat (causal effect relationship). Penelitian ini dilaksanakan guna mengetahui keefektifan metode imla' dalam menulis bahasa Arab siswa kelas XI MA Sumur Bandung Cililin Kabupaten Bandung Barat. Desain penelitian ini menggunakan one group pretest posttest design.

\begin{tabular}{|c|c|c|}
\hline Pretest & Treatment & Posttest \\
\hline $\mathrm{O}_{1}$ & $\mathrm{X}$ & $\mathrm{O}_{2}$ \\
\hline
\end{tabular}

Populasi yang diambil dalam penelitian ini adalah seluruh siswa kelas XI MA Sumur Bandung Cililin Kabupaten Bandung Barat yang berjumlah 37 siswa, dengan jumlah sampel siswa berjumlah 10 orang. Penelitian ini terdiri dari dua variabel, yaitu variabel X dan Variabel Y. Variabel X dalam penelitian ini adalah metode sedangkan variabel Y adalah imla'. Teknik pengumpulan data dalam penelitian ini menggunakan tes tulis (pretest dan posttest). Sedangkan teknik pengolahan data yang digunakan dalam penelitian ini adalah analisis deskriftif untuk mendapatkan data nilai rata-rata, validitas soal dan uji-t.

Rumus mencari nilai rata-rata: $\quad \bar{X}=\frac{\sum X_{i}}{N}$

(Sudjana, 2005:50)

$\bar{X}=$ skor rata-rata

$X_{\mathrm{i}}=$ skor setiap siswa

$\mathrm{N}=$ jumlah siswa.

Rumus mencari uji validitas:

$$
\begin{aligned}
& r_{x y}=\frac{N \sum X Y-\left(\sum X\right)\left(\sum Y\right)}{\sqrt{\left[N \sum X^{2}-\left(\sum X\right)^{2}\right]\left[N \sum Y^{2}-\left(\sum Y\right)^{2}\right]}} \quad \text { (Arikunto, 2006:107) } \\
& r_{x y}=\text { Koefisien variable X dan } Y \quad
\end{aligned}
$$


$\sum X=$ jumlah skor distribusi $X$

$\sum Y=$ jumlah skor distribusi $Y$

$\sum X^{2}=$ Jumlah kuadrat skor distribusi $X$

$\sum Y^{2}=$ Jumlah kuadrat skor distribusi $Y$

$\sum X Y=$ Jumlah perkalian skor $X$ dan $Y$.

Penarikan kesimpulan dari rumus diatas yaitu jika $\mathrm{r}_{x y} \geq \mathrm{r}$ tabel, maka $\mathrm{H}_{0}$ ditolak dan $\mathrm{H}_{1}$ diterima pada tingkat signifikansi $\alpha 5 \%$.

Rumus uji-t:

$\mathrm{MD}=$ Rata-rata dari selisih jumlah nilai

$$
\begin{aligned}
& M D=\frac{\sum D}{N} \\
& t=\frac{M D}{\sqrt{\frac{D^{2}-\frac{\left(\sum D\right)^{2}}{N}}{N(N-1)}}}
\end{aligned}
$$

$\Sigma \sim$ = Jumlah keseluruhan jumlah nilai

$\mathrm{N}=$ Jumlah Sampel

$\mathrm{T} \quad=$ Jumlah t-test

\section{Hasil dan Pembahasan}

\section{Macam-Macam Metode Imla'}

\section{Metode Imla' Manqul ( Menulis ulang dengan melihat teks)}

Maksud dari imla' manqul adalah para pelajar mengutip atau menulis potongan kalimat, baik teks buku, teks yang tertulis dipapan tulis, maupun dari teks yang tertulis disebuah kartu, setelah mereka selesai membacanya, mengeja huruf-hurufnya satu persatu dan memahaminya dengan pemahaman yang mendalam. Kemudian mereka menuliskannya dala buku catatan pelajaran milik mereka. Metode ini cocok untuk para pelajar yang masih dalam tingkatan dasar (pemula).

1. Keunggulan dan Keistimewaan Metode Imla' Manqul

a. Memperkuat kewaspadaan para pelajar, menumbuhkan minat untuk lebih bersungguh-sungguh dalam memperbaiki bentuk tulisan dan meningkatkan kemampuan mereka dalam menulis kalimat bahasa Arab.

b. Termasuk salah satu media yang tepat untuk memperoleh pengetahuan dalam bidang bahasa dan tulis-menulis. Dalam metode ini, para pelajar melakukan interaksi langsung dengan teks yang akan ditulis. Karena dalam prosesnya, mereka memperhatikan kata dan kalimat kutipan secara detail, baik dari segi susunan, bentuk, maupun maknanya. Setelah itu, mereka menuliskannya kembali pada buku catatan pelajaran.

c. Memudahkan para pelajar dalam menyerap makna kalimat kutipan. Lalu menyimpannya dalam memori pikiran sehingga mereka senantiasa mengingatnya. 
d. Membantu para pelajar untuk mengasah ketajaman daya ingat sehingga mereka mampu mengingat seluruh materi pelajaran dengan baik. Hal ini pada akhirnya mampu meminimalkan terjadinya kesalahan disatu sisi dan meningkatkan kewaspadaan (ketajaman pengamatan) disisi yang lain.

2. Tata Cara Penerapan Metode Imla' Manqul

a. Guru menyiapkan penggalan teks yang akan dijadikan sebagai bahan imla', lalu menuliskannya secara jelas dipapan tulis, atau menunjukannya secara gamblang jika tertulis pada sebuah kertas atau diktat.

b. Guru membacakan penggalan teks tersebut dengan bacaan yang jelas, fasih, dan lantang.

c. Kemudian para murid membacanya satu per satu membacanya kembali dengan tenang, tetapi dengan suara yang jelas. Metode ini bertujuan agar makna teks bisa merasuk kedalam pikiran dan terpatri didalam ingatan mereka. Setelah itu mereka disuruh untuk mengucapkan kembali redaksi teks beserta maknanya. Pada saat itulah, guru menilai kecepatan mereka dalam mengucapkan kalimat dan memastikan kebenaran pengucapannya.

d. Guru melatih anak didiknya dengan memberikan kata atau kalimat yang susah yang seperti dua kata yang berbeda, tetapi memiliki kemiripan bunyi pelapalan. Atau menguji mereka dengan memberikan kalimat yang salah, kemudian meminta slah seorang dari mereka untuk membacanya dengan teliti agar bisa menemukan bagian yang salah. Lebih baik lagi jika kata atau kalimat yang susah itu ditandai dengan warna yang berbeda atau diberi garis bawah.

e. Sebelum mendiktekan penggalan teks, guru memberikan aba-aba terlebih dahulu kepada anak didiknya untuk mepersiapkan diri sebelum meulai pembelajaran imla', misalnya meminta mereka mengeluarkan buku catatan, alat tulis atau alat-alat penunjang lainnya. Setelah mereka siap, guru boleh memulai imla' dengan membacakan penggalan teks, kata demi kata, kalimat demi kalimat, sambil menunjuk teks yang dibaca agar anak didiknya bisa melihat dan membacanya dengan jelas.

f. Setelah proses imla' selesai, guru harus mengulang kembali pembacaan penggalan teks imla'. Tetapi dengan tempo yang sedikit lebih cepat dari sebelumnya. Pengulangan ini ditujukan agar anak-anak didiknya memiliki kesempatan untuk membetulkan penulisan yang salah atau melengkapi bagianbagian yang belum lengkap.

g. Langkah selanjutnya adalah pemeriksaan atas hasil karya para murid. Guru memeriksa hasil tulisan mereka satu per satu. Jika ditemukan kesalahan, guru harus mengoreksi kesalahan anak diidknya dengan cara yang halus. Lalu guru mencontohkan kembali tulisan yang benar kepada mereka. Ketika guru memberi contoh, guru harus memberi kesempatan kepada mereka untuk membetulkan bentuk tulisan (khath), lalu menyalin kembali apa yang dicontohkan dipapan tulis, dan mendiskusikan kembali maknanya.

\section{Metode Imla' Manzhur (Menulis Ulang Tanpa Melihat Teks)}


Metode imla' manzhur tidak jauh dari metode imla' manqul. Hanya saja dalam metode imla' manzhur, seorang guru tidak memperlihatkan teks yang diimla'kan kepada anak didiknya, kecuali beberapa kata atau kalimat yang memang dipandang sulit bagi mereka.

3. Keunggulan dan Keistimewaan Metode Imla' Manzhur

a. Metode imla' manzhur diterapkan pada level yang lebih tinggi, yaitu satu tingkat diatas level pemula. Bagi para murid, tingkat kesukaran metode imla' manzhur lebih sulit dari metode sebelumnya, yaitu metode imla' manqul. Oleh karena itu, level metode imla' manzhur lebih tinggi dari pada metode imla' manqul.

b. Metode imla' manzhur mendorong para murid untuk meningkatkan konsentrasi dan daya ingat. Mereka dituntut untuk lebih fokus memperhatikan teks yang diucapkan oleh guru. Mereka juga dituntut untuk meningkatkan kapasitas ingatan agar dengan cepat mengingat teks yang diimla'kan, terutama mengingat kosakata atau kalimat yang dipandang sukar untuk diucapkan. Dengan metode pelatihan semacam itu, para murid akan memperoleh hasil lebih maksimal.

4. Tata Cara Penerapan Metode Imla' Manzhur

a. Langkah-langkah yang ditempuh dalam metode ini tidak berbeda jauh dengan langkah-langkah yang ditempuh dalam metode imla' manqul. Perbedaaan antara keduanya terletak pada saat murid menulis ulang kalimat yang dibacakan oleh guru, dan mereka tidak melihat contoh kalimatnya.

b. Setelah guru membacakan penggalan kalimat, mendiskusikan makna, dan menunjukan kosakata yang sukar, para murid tidak lagi melihat contoh kalimat ketika mereka menuliskannya. Dalam arti mereka menutup contoh kaliat tersebut. Kemudian menuliskannya kembali dengan benar.

c. Ketika proses imla' selesai, guru meeriksa hasil tulisan mereka dan memperlihatkan kesalahan-kesalahan (jika terdapat kesalahan). Kemudian guru mendiskusikannya kembali bersama mereka, sambil memberi contoh penulisan yang benar dipapan tulis. Setelah itu, guru meminta mereka untuk membetulkan bagian-bagian tulisan yang salah dengan merujuk pada apa yang telah dicontohkan dipapan tulis.

\section{Metode Imla' Istima'i (Menyimak)}

Yang dimaksud menyimak disini adalah mendengarkan kalimat atau teks yang dibacakan, lalu menulisnya. Metode ini sedikit lebih sukar dibandingkan dengan metode imla' manzhur, karena para pelajar dituntut untuk menulis kalimat atau teks tanpa melihat contoh tulisan dari guru, melainkan mengandalkan hasil pengetahuan mereka setelah mengikuti proses pembelajaran imla'. Denga begitu, guru bisa melakukan evaluasi. Hendaknya para kecermatan mereka dalam mendengarkan bacaan guru. Penerapan metode imla' ini dengan cara membacakan kalimat atau teks tertentu kepada para pelajar seperlunya. Setelah itu para pelajar diajak untuk mendiskusikan makna yang terkandung oleh kalimat atau teks tersebut, termasuk membicarakan kata-kata yang dianggap sulit. Setelah itu, baru para pelajar menuliskan kalimat atau teks yang dimaksud. 
Metode imla' ikhtibari adalah metode latihan dan ujian. Metode ini ditempuh untuk mengukur tingkat kemampuan para murid dan mengetahui sejauh mana hasil yang dicapai oleh mereka dalam belajar imla'. Dengan memberikan ujian atau latihan kepada mereka, seorang guru engetahui sedalam apa guru memberikan latihan atau ujian disesi akhir pada setiap level pembelajaran.

\section{Pembahasan}

Untuk membuktikan efektif tidaknya pembelajaran imla' terhadap peningkatan kemampuan menulis kalimat bahasa Arab peserta didik maka peneliti membandingkan hasil pre-test dan post-test, karena penelitian ini menggunakan satu kelas yaitu kelas eksperimen. Peneliti menyajikan data pre-tes untuk menggali data dan mengetahui kemampuan peserta didik kelas XI MA Sumur Bandung Cililin Kabupaten Bandung Barat sebelum diberikan treament. Adapun data pre-test yang dihasilkan adalah sebagai berikut:

Tabel 1 Nilai Pre-Tes Peserta Didik Kelas XI IPA

\begin{tabular}{|c|l|c|c|}
\hline No & \multicolumn{1}{|c|}{ Nama } & Jenis Kelamin & Nilai Pre Test \\
\hline 1 & Siswa-1 & P & 65 \\
\hline 2 & Siswa-2 & P & 70 \\
\hline 3 & Siswa-3 & L & 45 \\
\hline 4 & Siswa-4 & P & 50 \\
\hline 5 & Siswa-5 & L & 43 \\
\hline 6 & Siswa-6 & P & 44 \\
\hline 7 & Siswa-7 & L & 40 \\
\hline 8 & Siswa-8 & P & 35 \\
\hline 9 & Siswa-9 & L & 41 \\
\hline 10 & Siswa-10 & L & 25 \\
\hline 11 & Siswa-11 & P & 20 \\
\hline 12 & Siswa-12 & P & 60 \\
\hline 13 & Siswa-13 & P & 55 \\
\hline 14 & Siswa-14 & P & 64 \\
\hline 15 & Siswa-15 & P & 33 \\
\hline 16 & Siswa-16 & L & 44 \\
\hline 17 & Siswa-17 & L & 32 \\
\hline 18 & Siswa-18 & L & 32 \\
\hline 19 & Siswa-19 & L & 31 \\
\hline 20 & Siswa-20 & P & 54 \\
\hline 21 & Siswa-21 & L & 30 \\
\hline 22 & Siswa-22 & P & 63 \\
\hline 23 & Siswa-23 & P & 62 \\
\hline 24 & Siswa-24 & & 50 \\
\hline 25 & Siswa-25 & P & \\
\hline 26 & Siswa-26 & P & \\
\hline
\end{tabular}




\begin{tabular}{|l|l|l|l|}
\hline 27 & Siswa-27 & L & 61 \\
\hline 28 & Siswa-28 & P & 45 \\
\hline 29 & Siswa-29 & L & 30 \\
\hline 30 & Siswa-30 & P & 30 \\
\hline 31 & Siswa-31 & P & 32 \\
\hline 32 & Siswa-32 & P & 25 \\
\hline 33 & Siswa-33 & P & 40 \\
\hline 34 & Siswa-34 & P & 50 \\
\hline 35 & Siswa-35 & P & 62 \\
\hline 36 & Siswa-36 & P & 33 \\
\hline 37 & Siswa-37 & & \\
\hline
\end{tabular}

Berdasarkan hasil pre-test di atas dapat di deskripsikan sebagai berikut:

Tabel 2 Deskripsi Hasil Pre-test Peserta Didik Kelas XI IPA

\begin{tabular}{|l|c|}
\hline \multicolumn{1}{|c|}{ Perhitungan } & Nilai \\
\hline Mean & 49 \\
\hline Standar Deviasi & 13,7 \\
\hline Max & 70 \\
\hline Min & 29 \\
\hline
\end{tabular}

Dari tabel di atas didapatkan bahwa untuk nilai pretes rata-rata $=49$, standar deviasi $=13,7$, nilai maksimum $=70$ dan nilai minimum $=29$.

Untuk menggali data dan kemampuan peserta didik kelas XI MA Sumur Bandung Cililin Kabupaten Bandung Barat setelah dilakukan treatment, maka peneliti menyajikan data post-test dengan hasil sebagai berikut:

Tabel 3 Nilai Pos-Tes Peserta Didik Kelas XI IPA

\begin{tabular}{|c|l|c|c|}
\hline No & \multicolumn{1}{|c|}{ Nama } & Jenis Kelamin & Nilai Pre Test \\
\hline 1 & Siswa-1 & P & 82 \\
\hline 2 & Siswa-2 & P & 88 \\
\hline 3 & Siswa-3 & L & 76 \\
\hline 4 & Siswa-4 & P & 78 \\
\hline 5 & Siswa-5 & L & 76 \\
\hline 6 & Siswa-6 & L & 78 \\
\hline 7 & Siswa-7 & P & 76 \\
\hline 8 & Siswa-8 & L & 76 \\
\hline 9 & Siswa-9 & P & 78 \\
\hline 10 & Siswa-10 & L & 76 \\
\hline 11 & Siswa-11 & L & 76 \\
\hline 12 & Siswa-12 & P & 82 \\
\hline 13 & Siswa-13 & P & 81 \\
\hline 14 & Siswa-14 & & 86 \\
\hline
\end{tabular}




\begin{tabular}{|l|l|l|l|}
\hline 15 & Siswa-15 & P & 84 \\
\hline 16 & Siswa-16 & P & 80 \\
\hline 17 & Siswa-17 & L & 82 \\
\hline 18 & Siswa-18 & L & 78 \\
\hline 19 & Siswa-19 & L & 76 \\
\hline 20 & Siswa-20 & P & 76 \\
\hline 21 & Siswa-21 & L & 83 \\
\hline 22 & Siswa-22 & L & 76 \\
\hline 23 & Siswa-23 & P & 88 \\
\hline 24 & Siswa-24 & P & 83 \\
\hline 25 & Siswa-25 & P & 78 \\
\hline 26 & Siswa-26 & L & 88 \\
\hline 27 & Siswa-27 & P & 78 \\
\hline 28 & Siswa-28 & L & 80 \\
\hline 29 & Siswa-29 & P & 76 \\
\hline 30 & Siswa-30 & P & 76 \\
\hline 31 & Siswa-31 & L & 76 \\
\hline 32 & Siswa-32 & P & 78 \\
\hline 33 & Siswa-33 & P & 76 \\
\hline 34 & Siswa-34 & P & 82 \\
\hline 35 & Siswa-35 & P & 80 \\
\hline 36 & Siswa-36 & & 76 \\
\hline 37 & Siswa-37 & \\
\hline
\end{tabular}

Berdasarkan hasil pre-test di atas dapat di deskripsikan sebagai berikut:

Tabel 4 Deskripsi Hasil Post Tes Peserta Didik Kelas XI IPA

\begin{tabular}{|l|c|}
\hline \multicolumn{1}{|c|}{ Perhitungan } & Nilai \\
\hline Mean & 79 \\
\hline Standar Deviasi & 4,04 \\
\hline Max & 88 \\
\hline Min & 76 \\
\hline
\end{tabular}

Dari tabel di atas didapatkan bahwa untuk nilai post-tes rata-rata $=79$, standar deviasi $=4,04$, nilai maksimum $=88$ dan nilai minimum $=76$

Berdasarkan data yang telah dipaparkan diatas dapat diambil kesimpulan bahwa untuk mengetahui ada dan tidaknya pengaruh metode imla' terhadap kemampuan siswa dalam menulis bahasa Arab, yaitu dengan menggunakan uji-t. Adapun hipotesisnya adalah sebagai berikut :

$\mathbf{H}_{\mathbf{o}}$ : $\mathbf{T}_{\text {hitung }} \leq \mathbf{T}_{\text {tabel, }}$ maka Tidak ada perbedaan yang signifikan dalam kemampuan menulis dikte Arab sebelum diterapkan dengan sesudah diterapkan metode Imla.

$\mathbf{H}_{\mathbf{a}} \mathbf{T}_{\text {hitung }}>\mathbf{T}_{\text {tabel, }}$ maka Ada perbedaan yang signifikan dalam kemampuan menulis dikte Arab sebelum diterapkan dengan sesudah diterapkan metode Imla. 
Kemudian akan dilakukan perhitungan awal untuk pengujian hipotesis yang akan disajikan dalam tabel di bawah ini:

Tabel 5 Tabel Perhitungan Untuk Uji Hipotesis

\begin{tabular}{|c|c|c|c|c|c|}
\hline No & Nama & Nilai Pre Test & Nilai Pos-Tes & D & $\mathbf{D}^{2}$ \\
\hline 1 & Siswa-1 & 65 & 82 & 17 & 289 \\
\hline 2 & Siswa-2 & 70 & 88 & 18 & 324 \\
\hline 3 & Siswa-3 & 45 & 76 & 31 & 961 \\
\hline 4 & Siswa-4 & 50 & 78 & 28 & 784 \\
\hline 5 & Siswa-5 & 43 & 76 & 33 & 1089 \\
\hline 6 & Siswa-6 & 44 & 78 & 34 & 1156 \\
\hline 7 & Siswa-7 & 40 & 76 & 36 & 1296 \\
\hline 8 & Siswa-8 & 35 & 76 & 41 & 1681 \\
\hline 9 & Siswa-9 & 41 & 78 & 37 & 1369 \\
\hline 10 & Siswa-10 & 25 & 76 & 51 & 2601 \\
\hline 11 & Siswa-11 & 20 & 76 & 56 & 3136 \\
\hline 12 & Siswa-12 & 60 & 82 & 22 & 484 \\
\hline 13 & Siswa-13 & 55 & 81 & 26 & 676 \\
\hline 14 & Siswa-14 & 59 & 86 & 27 & 729 \\
\hline 15 & Siswa-15 & 64 & 84 & 20 & 400 \\
\hline 16 & Siswa-16 & 33 & 80 & 47 & 2209 \\
\hline 17 & Siswa-17 & 44 & 82 & 38 & 1444 \\
\hline 18 & Siswa-18 & 32 & 78 & 46 & 2116 \\
\hline 19 & Siswa-19 & 32 & 76 & 44 & 1936 \\
\hline 20 & Siswa-20 & 31 & 76 & 45 & 2025 \\
\hline 21 & Siswa-21 & 54 & 83 & 29 & 841 \\
\hline 22 & Siswa-22 & 30 & 76 & 46 & 2116 \\
\hline 23 & Siswa-23 & 63 & 88 & 25 & 625 \\
\hline 24 & Siswa-24 & 60 & 88 & 28 & 784 \\
\hline 25 & Siswa-25 & 62 & 83 & 21 & 441 \\
\hline 26 & Siswa-26 & 50 & 78 & 28 & 784 \\
\hline 27 & Siswa-27 & 61 & 88 & 27 & 729 \\
\hline 28 & Siswa-28 & 45 & 78 & 33 & 1089 \\
\hline 29 & Siswa-29 & 30 & 80 & 50 & 2500 \\
\hline 30 & Siswa-30 & 30 & 76 & 46 & 2116 \\
\hline 31 & Siswa-31 & 32 & 76 & 44 & 1936 \\
\hline 32 & Siswa-32 & 25 & 76 & 51 & 2601 \\
\hline 33 & Siswa-33 & 40 & 78 & 38 & 1444 \\
\hline 34 & Siswa-34 & 50 & 76 & 26 & 676 \\
\hline 35 & Siswa-35 & 56 & 82 & 26 & 676 \\
\hline 36 & Siswa-36 & 62 & 80 & 18 & 324 \\
\hline
\end{tabular}




\begin{tabular}{|c|c|c|c|c|c|}
\hline 37 & Siswa-37 & 33 & 76 & 43 & 1849 \\
\hline \multicolumn{2}{|c|}{ TOTAL } & $\mathbf{1 6 7 1}$ & $\mathbf{2 9 4 7}$ & $\mathbf{1 2 7 6}$ & $\mathbf{4 8 2 3 6}$ \\
\hline
\end{tabular}

Selanjutnya peneliti akan melakukan kriteria uji hipotesis dengan rumus:

$$
\begin{aligned}
& M D=\frac{\sum D}{N} \\
& =\frac{1276}{37} \\
& =34,486
\end{aligned}
$$

Kemudian menghitung nilai t:

$$
\begin{aligned}
& t=\frac{M D}{\sqrt{\frac{D^{2}-\frac{\left(\sum D\right)^{2}}{N}}{N(N-1)}}} \\
& t=\frac{34,4876}{\sqrt{\frac{48236-\frac{(1276)^{2}}{37(36)}}{37}}} \\
& t=\frac{34,4876}{\sqrt{\frac{48236-\frac{1628176}{37}}{37(36)}}} \\
& t=\frac{34,4876}{\sqrt{\frac{48236-44004,75}{1332}}} \\
& t=\frac{34,4876}{\sqrt{\frac{4231,25}{1332}}} \\
& t=10,87
\end{aligned}
$$

Setelah dilakukan perhiTungan, maka didapatkan bahwa:

$$
\mathrm{T}_{\text {hitung }}=10,87
$$

$\mathrm{T}_{\text {tabel }}=1,687$

Hal ini berarti $\mathrm{T}_{\text {hitung }}$ lebih besar dari $\mathrm{T}_{\text {tabel. }}$ Berdasarkan hal tersebut dapat disimpuklan bahwa: Ada perbedaan yang signifikan dalam kemampuan menulis dikte Arab sebelum diterapkan dengan sesudah diterapkan metode imla.

Proses pembelajaran dalam penelitian ini disajikan sebanyak 3 kali pertemuan, yaitu pertemuan pertama penyajian pretest, pertemuan kedua penyajian treatment, dan pertemuan ketiga penyajian posttest

Berdasarkan hasil yang diperoleh menunjukkan bahwa pembelajaran imla' dapat meningkatkan kemampuan menulis kalimat dalam pembelajaran bahasa Arab dengan membandingkan nilai rata-rata peserta didik untuk pre-test $=49$ Standar deviasi pre-test $=13,7$, nilai maksimum $=70$ dan nilai minimum $=29$.

Postest diberikan setelah treatment, hasil tersebut dapat dibuktikan dengan nilai rata-rata posttest $=79$, standar deviasi $=4,04$, nilai maksimum $=88$ dan nilai minimum = 76. Sehingga penelitian ini dapat dikategorikan baik dengan melihat perbedaan hasil dari sebelum diberikan treatment dan setelah diberikan treatmen. Untuk mengetahui efektif atau tidaknya metode imla maka peneliti menggali data dengan melakukan uji-t. 
Adapun data yang diperoleh dari hasil uji-t dalam penelitian ini, bahwa $t_{\text {hitung }}$ $(10,87)>t_{\text {tabel }}=1,687$ dengan taraf signifikan $\alpha 5 \%$. Berdasarkan kriteria hasil uji hipotesis bahwa $\mathrm{H}_{\mathrm{o}}$ : $\mathrm{X}_{1}=\mathrm{X}_{2}$, Artinya: Tidak ada perbedaan yang signifikan dalam kemampuan menulis dikte Arab sebelum diterapkan dengan sesudah diterapkan metode imla. $\mathrm{H}_{\mathrm{a}}: \mathrm{X}_{1} \neq \mathrm{X}_{2}$, Artinya: Ada perbedaan yang signifikan dalam kemampuan menulis dikte Arab sebelum diterapkan dengan sesudah diterapkan metode imla. Hal ini berarti metode imla' efektif dalam meningkatkan kemampuan siswa kelas XI MA Sumur Bandung Cililin Kabupaten Bandung Barat.

Berdasarkan data tersebut Pembelajaran dengan menggunakan metode imla' dapat meningkatkan kemampuan siswa menulis bahasa Arab kelas XI MA Sumur Bandung Cililin Kabupaten Bandung Barat. Peningkatan tersebut dapat dilihat dari meningkatnya kemampuan menulis bahasa Arab pada siswa dan juga meningkatnya sikap dan motivasi siswa dalam mengikuti pembelajaran.

\section{Kesimpulan}

Berdasarkan hasil uji-t dalam penelitian ini, bahwa $t_{\text {hitung }}(10,87)>t_{\text {tabel }}=1,687$ dengan taraf signifikan $\alpha 5 \%$. Hal ini dpat diartikan $\mathrm{H}_{0}$ ditolak dan $\mathrm{H}_{1}$ diterima. Dengan hal ini maka Pembelajaran dengan menggunakan metode imla' dapat meningkatkan kemampuan siswa menulis bahasa Arab kelas XI MA Sumur Bandung Cililin Kabupaten Bandung Barat.

\section{Daftar Pustaka}

Akmal, Hijrat Lalu. (2020). Pembelajaran Khat Wa Qowa'idul Imla' Mahasiswa Uin Mataram Dan Problematikanya, Al-Islamiyah, Vol.2,(No.1), 3.

Arikunto, S. (2006). Prosedur Penelitian Suatu Pendekatan Praktik. Jakarta: Rineka Cipta. Atika, Rr Nur Aprianti. Muassomah. (2020). Penggunaan Media Kahoot! Sebagai Media Pembelajaran Maharah Kitabah (imla') Bahasa Arab di Era Industri 4.0, Lisanan Arabiya, Vol.4, (No.2).

Fauziah, Reni. Mahyudin Ritonga. Fitri Alrasi. (2020). Korelasi Tsiqah Tahfidz Al-Qur'an Dengan Maharah Al-Lughah Al-'Arabiyyah Mustawa Tsalits Ma'had Az-Zubair Bin Al-Awwam. El-Tsaqafah, Vol.19, (No.1), 28.

Ghani, A. A. (2020). Panduan Lengkap Belajar Imla' Dan Menulis Arab Otodidiak. Jakarta Selatan: Turos.

Hanafy, Muh. Sain. (2014). Konsep Belajar Dan Pembelajaran, Lentera Pendidikan, Vol.17 (No.1)

Prihartini, Yogia, Wahyudi. Nuraini. (2018). Peningkatan Maharah Al Kitabah Melalui Penerapan Media Lauhah Al Juyub Pada Siswa Mtsn Aceh Utara. Jurnal Literasiologi, Vol.1, (No.1), 60.

Sudjana. (2005). Penilaian Hasil Proses Belajar Mengajar. Bandung: PT Remaja Rosdakarya.

Wagiran. (2005). Pemerolehan Bahasa dan Pengaruhnya terhadap Pengajaran Bahasa. Semarang: UNNES Press 
